\title{
Proposed Derivation of the Integrated Capability Maturity Model as an Environmental Management Maturity Model
}

\author{
Daniel Adrian Doss ${ }^{1, *}$, Raymond Tesiero ${ }^{1}$, Balakrishna Gokaraju ${ }^{1}$, David McElreath ${ }^{2}$, Rebecca Goza ${ }^{3}$ \\ ${ }^{1}$ College of Business and Technology, University of West Alabama, United States \\ ${ }^{2}$ School of Applied Sciences, University of Mississippi, United States \\ ${ }^{3}$ College of Business, University of Central Oklahoma, United States
}

Copyright $\bigcirc 2017$ by authors, all rights reserved. Authors agree that this article remains permanently open access under the terms of the Creative Commons Attribution License 4.0 International License

\begin{abstract}
This article highlights the adaptability of the integrated Capability Maturity Model within the context of a environmental process maturity framework. Existing maturity models are applicable in a variety of quality contexts - quality management, quality control, and quality assurance. The reviewed literature is synthesized to propose a process improvement maturity model derivative to address environmental management processes.
\end{abstract}

Keywords Capability Maturity Model, Environmental Management, Maturity Model, Process Improvement, Process Maturity, Quality Assurance, Quality Control

\section{Introduction}

Two types of endangerments threaten society: man-made and natural calamities [1, 2]. Often, such events occur with speed, surprise, and violence with little or no warning. In a variety of cases, such disasters result in environmental damages that must be addressed via some form of methodical process throughout preparation, mitigation, response, and recovery initiatives $[1,2]$.

Historically, an example of a devastating calamity was the 1989 Exxon Valdez oil spill near the Alaskan shoreline. The incident resulted in the spillage of roughly "between 260,000 and 750,000 barrels of crude oil” [1]. This quantity of barrels represented approximately 11 million gallons of crude released into the ecosystem [3].

The 2005 Hurricane Katrina resulted in substantial environmental damage. At least 90,000 $\mathrm{mi}^{2}\left(223,000 \mathrm{~km}^{2}\right)$ were derelict with debris and waste [4]. The storm resulted in approximately 7 million gallons of oil spilled, a total of 575 chemical spills, and damages to four hazardous waste locations [4]. Numerous amounts of sewage, toxins, and petrochemicals were released into the environment [4].
During 2010, the British Petroleum oil spill garnered international attention. The incident surpassed the Exxon Valdez as the worst oil spill in U.S. history. It resulted in 11 deaths, and oil spilled for 87 days before capping occurred [5]. The spillage amassed a quantity of approximately 5 million barrels of oil being released in the Gulf of Mexico [5]. The corresponding oil slick affected approximately 4,200 miles of shoreline ("roughly five times the length of California”) [5, p. 115].

Any nation is susceptible to calamity and disaster, including those events that involve environmental situations. For instance, in the United Kingdom, as a result of the Great London Smog of 1952, increases in both morbidity and mortality were observed after increases in polluted air occurred [6]. After the incident, approximately 4,000 individuals died from bronchial illness related to the smog [7]. The smog's composition was determined to have greater acidity than lemon juice resulting from its sulphuric acid content [7].

The preceding calamities and disasters resulted from either man-made or natural origins. Regardless of their respective origins, they resulted in much devastation. Despite the implementation of methodical plans to address the needs of each situation uniquely, processes associated with the respective mitigations, responses, and recoveries did not implement specifically any progressive framework that emphasized maturity of process.

However, in the software engineering domain, such a model exists: the Capability Maturity Model (CMM). A variety of derivatives exist whereby adaptations of the CMM have been applied to unrelated domains and disciplines (e.g., project management, human resources, etc.). Given these notions, this article continues the lineage of articles devoted to process maturity modeling and derivatives of the CMM and the integrated CMM (CMMi). More specifically, this article poses a derivative process improvement framework within the context of environmental management. 
Essentially, a conceptual framework is presented herein as a catalyst and reference for future research endeavors.

\section{Materials and Methods}

This article reviews existing works regarding process improvement maturity models, synthesizes the findings, and proposes a derivative process improvement framework within the context of the environmental management domain. Essentially, this article proposes a conceptual framework that may be beneficial for other seeking to pursue research in the areas of process improvement or environmental management processes.

\subsection{Theoretical Frameworks}

The theoretical frameworks for this article are the CMM and the CMMi. Typically, maturity model frameworks represent progressive, sequential paradigms for improving organizational processes via an evolutionary, five-phase paradigm. Typically, the basic stages of process maturity modeling paradigms are as follows: 1) immature, ad hoc, random processes, 2) reactive and managed processes, 3) understandable and expressed processes, 4) quantitatively managed processes, and 5) optimized processes [8, 9, 10]. Generally, framework models derived from the CMM and CMMi incorporate some or all of these phases within their fundamental architecture. The following table highlights these concepts.

Table 1. Sequential Maturity Model Stages

\begin{tabular}{|c|l|l|}
\hline $\begin{array}{c}\text { Maturity } \\
\text { Level }\end{array}$ & \multicolumn{1}{|c|}{$\begin{array}{c}\text { Maturity } \\
\text { Stage/Phase }\end{array}$} & \multicolumn{1}{|c|}{ Maturity Level Description } \\
\hline 1 & $\begin{array}{l}\text { Initial and } \\
\text { commencing }\end{array}$ & $\begin{array}{l}\text { Processes are generally deemed } \\
\text { to be random, unstructured, ad } \\
\text { hoc, informal, etc. In some cases, } \\
\text { a process may not exist. Process } \\
\text { maturity is absent. }\end{array}$ \\
\hline 2 & $\begin{array}{l}\text { Reactive and } \\
\text { managed }\end{array}$ & $\begin{array}{l}\text { Processes may exist among } \\
\text { projects, but exhibit reactiveness. }\end{array}$ \\
\hline 3 & Defined & $\begin{array}{l}\text { Processes exist among projects } \\
\text { and within organizations } \\
\text { commensurate with standards. } \\
\text { Processes become proactive } \\
\text { instead of reactive. }\end{array}$ \\
\hline 4 & $\begin{array}{l}\text { Quantitatively } \\
\text { managed }\end{array}$ & $\begin{array}{l}\text { Processes are examined } \\
\text { quantitatively for the purposes of } \\
\text { control and measurement. }\end{array}$ \\
\hline 5 & Optimized & $\begin{array}{l}\text { Processes are optimized to } \\
\text { minimize wastefulness and to } \\
\text { improve efficiency without } \\
\text { compromising effectiveness. } \\
\text { Continuous emphasis regarding } \\
\text { process improvement. }\end{array}$ \\
\hline
\end{tabular}

This theoretical model reflecting the foundational, five-phase process maturity framework is considered herein to show similar stages for improving environmental processes. The stages are progressive and sequential. Before any succeeding level is achieved, the requirements of both the previous and current levels must be satisfied. However, any changes within the process environment may interject change that causes processes to regress to a lowered maturity level. Because each organization is unique, it is beyond the scope of this article to provide specific application paradigms for entities seeking to implement the proposed construct.

\subsection{Existing Approaches and Processes}

Regarding environmental management and corresponding people-oriented systems, process improvement may be facilitated via some consideration of the following categories: 1 ) reviews of product portfolios using life cycle perspectives, 2) procedures and responsibilities, 3) project implementation, and 4) auditing and evaluating [11]. This approach accommodates continuous performance improvement [11]. Essentially, this perspective of environmental management necessitates quality considerations of "process quality" [11, p. 4].

Another approach involves using process mapping as the methodological guide for generating environmental management process improvement [12]. Similarly, certification may also be used as an approach to generating environmental process improvement [12]. Through certification, improved competitiveness may occur organizationally whereby environmental management may be deemed beneficial economically [12].

Regulation and policy are also methods of influencing organizational processes. For instance, federal entities may negotiate some types of legal agreements with "regulatory authorities" regarding the "environmental conditions" that may exist at a specific location [13, p. 28]. Regulation is also attributed to generating process improvements with respect to operational reliability and hazard reductions [14].

\subsection{Absence of a Maturity Model Approach}

The preceding discussions approached environmental management from dominantly policy, regulatory, certification, and quality perspectives without emphasizing the maturity of any underlying processes themselves. Thus, former discussions have yielded little regarding environmental management process improvement from the perspective of a maturity framework. Essentially, the existing and historical approaches are commensurate with traditional forms of generating improvement via some implementation of quality management or the exercising of regulation or policy.

\section{Highlights of the Literature}

This article reviews existing works regarding process improvement maturity models, synthesizes the findings, and 
proposes a derivative process improvement framework within the context of the environmental management domain. This article addresses this literary shortcoming by synthesizing the reviewed process maturity literature to propose an adaptation framework within the context of environmental management processes. Thus, the literature review considers existing derivative CMM and CMMi framework models that have been proposed or investigated among a variety of different disciplines and domains thereby establishing (to a degree) its potentials for domain mobility and applicability.

\subsection{Maturity Modeling Derivatives and Research}

The CMM/CMMi frameworks have origins in the software industry. Investigations of maturity modeling framework benefits have shown efficacy for the fundamental architecture of the maturity model. For instance, after implementation, Raytheon exhibited a "twofold increase" of productivity and an approximate "return ratio of 7.7 to 1 ” concerning its expenditures for improvements [15]. Essentially, these enhancements reflected savings of approximately $\$ 4.48$ million generated from an investment of $\$ 0.58$ million [15].

The maturity framework has been investigated within the context of project management. Specifically, during the 1990s, the potential of relationship between software development activities, process maturity, and project performance was investigated [16]. It was shown that the maturity of software process management is associated positively with the performance of a project [16]. Following the turn of the century, the project management perspective reflected a unique maturity model deemed the project management maturity model (PMMM) [17]. The PMMM incorporates a five-stage approach to process improvement that is commensurate with the fundamental improvement phases reflected in the CMM/CMMi [17].

The discipline of education also accommodates process improvement frameworks that invoke the CMM/CMMi concept. A maturity model from the perspective of e-learning environments exists in the education domain [18]. This paradigm differs somewhat from the original CMM/CMMi contexts with respect to focus areas of its compositional phases. Specifically, the model's stages are: 1) ad hoc, 2) e-learning objective establishment, 3) process definition, 4) ensuring quality for e-learning and 5) continuous improvement [18]. Another derivative is found within the context of computing education. This version's framework addresses ratings of educational organizations with respect to their potential of delivering education [19]. It incorporates a five-stage approach that reflects the original CMM/CMMi intentions [19].

The security and policing domains also possess respective maturity models for process improvement. However, in this instance, the model exhibits a six-stage progression throughout its respective phases [20].
Specifically, these phases consist of: 1) non-existent processes, 1) ad hoc, random processes, 2) intuitive, repeatable processes, 3) defined processes, 4) measurable and managed processes, and 5) optimized processes [20]. Regarding the policing context, the proposed criminal justice maturity model (CJMM) incorporates the fundamental CMMi phases as an architectural framework for generating process improvement within the justice domain [21].

Industry and manufacturing also exhibit process improvement maturity models. The industrial process maturity model incorporates a five-phase improvement paradigm that incorporates the CMM stages as its inspiration [8]. The Sustainability Manufacturing Maturity Model (SMMM) also incorporates a systematic approach to improving processes [22]. However, its inspiration is taken from life cycle management principles [22].

With respect to environmental management, the literature showed an environmental maturity model (EMM) that incorporates the CMM as its fundamental premise [23]. The proposed EMM provides a paradigm for bolstering process maturity among environments that select to implement the improvement method [23]. Essentially, via EMM implementation, organizations may improve their abilities to enact processes associated with environmental management functions [23].

Additional derivation areas include quality management, information security, industrial applications, contract management, human resources, quality, financial management, and management control systems [24, 25, 26, 27, 28, 29, 30, 31, 32, 33, 34, 35, 36].

The reviewed literature shows the portability of the fundamental CMM and CMMi frameworks among unrelated domains and disciplines as baseline architectures to support process improvement endeavors. Although numerous derivative models exist, only one existed (EMM) to support the environmental management context via the incorporating of the CMM as its framework. However, it did not incorporate the CMMi within its framework. Despite the presence of the EMM within the reviewed literature, none of the remaining models addressed the context of environmental management using strictly the CMMi as its inspirational and fundamental architectural basis.

\section{Environmental Maturity Model}

All entities commence the crafting of any maturity model derivative at the initial stage of randomness with respect to the process setting [10]. The reviewed maturity models, regardless of the respective domains and disciplines, all incorporated a progressive framework for maturing processes through time. Given these notions, a proposed model may be crafted within the context of environmental process improvement using the basic maturity framework as its fundamental architecture. 
Commensurate with existing models and frameworks, derived from the CMMi, the proposed EMM improvement stages are:

1) immature, ad hoc, random processes,

2) reactive and managed processes,

3) understandable and expressed processes,

4) quantitatively managed processes, and

5) optimized processes.

Each stage would be experienced sequentially, and progression to the next stage would be impossible unless the requirements of the current stage were satisfied. Derived from the foundational maturity model framework presented within Table 1, Table 2 shows the proposed stages of the EMM framework using the CMMi as its fundamental premise.

Each instance of disaster or calamity is unique with respect to its environmental considerations. Given this notion, the framework model may be further crafted to address organizational processes corresponding to specific types of environmental calamities, such as oil spills, earthquakes, massive storms, and so forth. By doing so, organizations may gain the opportunity to enhance their environmental process robustness with respect to an array of different situations.

\subsection{Case Consideration}

Application of the proposed EMM may be considered from the perspective of a 2004 MFG Chemical plant explosion in Dalton, Georgia wherein at least 200 families were evacuated from their respective homesteads, and 154 received medical treatment and were decontaminated for chemical exposure [37]. Considering the proposed EMM with respect to the Georgia scenario provides insight regarding the potentials of process improvement for both the manufacturing company and first-responders. The incident response was characterized by an overall state of unpreparedness thereby signaling attributes of EMM level 1 status. Essentially, an unprepared response occurred to the incident. This incident involved the releasing of allyl chloride and alcohol from a reactor after a vicious, uncontrolled chemical reaction "rapidly pressurized a 4,000-gallon chemical reactor, activating an emergency vent" [37, p. 1]. Contributing causes to this event were identified as poor designs among "process controls, instrumentation, and safety systems" [37, p. 1]. Additionally, the initial first-responder personnel were untrained for such a disaster, and had no protective equipment [37].

Table 2. Proposed EMM Construct

\begin{tabular}{|c|c|c|c|}
\hline Maturity Level & Maturity Stage/Phase & Maturity Level Description & Concept \\
\hline 1 & Initial and commencing & $\begin{array}{l}\text { Processes are generally deemed to be random, } \\
\text { unstructured, ad hoc, informal, etc. In some cases, } \\
\text { a process may not exist. Process maturity is } \\
\text { absent. }\end{array}$ & $\begin{array}{l}\text { Lack of formal response to a disaster impacting } \\
\text { the environment. Response is reactive and } \\
\text { unstructured. Response may be unprepared. }\end{array}$ \\
\hline 2 & Reactive and managed & $\begin{array}{l}\text { Processes may exist among projects, but exhibit } \\
\text { reactiveness. }\end{array}$ & $\begin{array}{l}\text { Process to initiate some type of safety protocol } \\
\text { or response after a certain threshold is } \\
\text { surpassed. However, no preventive mechanism } \\
\text { existed to prevent or mitigate disaster. }\end{array}$ \\
\hline 3 & Defined & $\begin{array}{l}\text { Processes exist among projects and within } \\
\text { organizations commensurate with standards. } \\
\text { Processes are defined, expressed, and repeatable. } \\
\text { Processes become proactive instead of reactive. }\end{array}$ & $\begin{array}{l}\text { Proactive processes may adhere to certain tenets } \\
\text { of International Organization for } \\
\text { Standardization (ISO), client standards, } \\
\text { organizational standards, professional } \\
\text { standards, and so forth. }\end{array}$ \\
\hline 4 & Quantitatively managed & $\begin{array}{l}\text { Processes are examined quantitatively for the } \\
\text { purposes of control and measurement. }\end{array}$ & $\begin{array}{l}\text { Quantitative assessment occurs against } \\
\text { processes for a variety of response, such as } \\
\text { improving logistics flows, decreasing response } \\
\text { times to disaster events, and so forth. } \\
\text { Quantitative assessment may range from } \\
\text { statistical analysis to methods of linear } \\
\text { optimization. }\end{array}$ \\
\hline 5 & Optimized & $\begin{array}{l}\text { Processes are optimized to minimize wastefulness } \\
\text { and to improve efficiency without compromising } \\
\text { effectiveness. Continuous emphasis regarding } \\
\text { process improvement. }\end{array}$ & $\begin{array}{l}\text { A finely honed process exists that is efficient, } \\
\text { repeatable, and effective whereby the } \\
\text { sponsoring organization maximizes its potential } \\
\text { to respond to environmental calamities. }\end{array}$ \\
\hline
\end{tabular}


With respect to the proposed EMM, no guarantees exist that an explosion was unavoidable. However, through implementation of maturity modeling, specific processes for handling potential emergency scenarios would exist with respect to identified endangerments that result from the crafting of threat matrices. Such activities are not uncommon within the context of emergency contingency planning and strategies [1]. Through process specification, practice, and improvement, both the chemical company and responding organization may have fielded stronger responses to the incident because specific process steps and requisite equipment would have been identified and available. Thus, statuses regarding the second and third maturity levels are corresponding levels of the proposed EMM framework. Repeated practice and assessment of the incident exercises provide insight regarding organizational performance and improvement opportunities [38]. Certainly, such improvements could be considered from the perspective of quantification of risk assessment [38]. After incorporating noted improvements, overall processes would be unceasingly considered for improvement. This activity is commensurate with level 5 of the proposed EMM. Additionally, ongoing improvement is commensurate with the continuous improvement quality tenet of emergency management processes [39].

\subsection{Best Practice}

The use of the proposed EMM in conjunction with the crafting of best practices would not be unimaginable. From the perspective of maturity modeling, at the initial level, examples of such activities include defining "standard development, maintenance and support processes, lifecycle models in use, pre-tailored process descriptions, specific methods for analysis, design, construction, and testing” [40, p. 290]. Typically, the maturity model framework assists toward identifying and crafting best practices organizationally [40, 41]. Thus, application of the proposed EMM may be beneficial for organizations seeking to identify best practices that improve processes that involve or impact the environment.

\section{Conclusions}

The reviewed literature showed an absence of any environmental management paradigm used for improving processes necessary for preparing for, mitigating, reacting to, or responding to substantial disasters involving some environmental conditions or situations. However, a process improvement framework, using maturity of process as its basis, exists among unrelated domains. More specifically, derivatives of the CMMi and CMM have been adapted to generate process improvements in a variety of different disciplines and domains, such as finance, industrial management, systems control, and several others. Given the existences of such derivatives, the foundational architecture of the process improvement paradigm shows the potentials of adaptability and portability among different venues.

The maturity modeling concepts has origins in the discipline of software engineering. Some evidence exists regarding its portability among unrelated domains whereby specific derivatives of the basic framework are applicable to numerous situations, ranging from human resources processes to quality assurance processes. Thus, the basic construct is robust to a variety of domain-specific venues. However, the reviewed literature revealed no use of the maturity model framework within the context of emergency management involving natural disasters impacting the environment.

The introduction section described a variety of different man-made and natural disasters that resulted in environmental damage. Through invoking a maturity-based process paradigm, response organizations and government agencies may improve not only the efficiency and effectiveness of the emergency management cycle, but also may improve the timeliness of addressing calamities. Thus, the proposed EMM framework may have homeland security and emergency management applications. It is recommended that future research examine maturity modeling frameworks as supplements within the stages of the emergency management cycle.

Given these notions, future research may investigate the potential of adaptability and efficacy of the EMM with respect to environmental management process improvement considerations. Future studies may examine a variety of incidents reflecting both man-made and natural calamities as catalysts for organizational processes that necessitate environmental management functions. In this regard, organizations may enact the EMM or some derivative thereof in conjunction with post-event analysis. By doing so, organizations may identify where realistic inefficiency and ineffectiveness exist among implemented processes. Through feedback gleaned from review of these processes, organizations may integrate knowledge and understanding throughout the EMM phases to bolster their respective environmental management processes.

\section{REFERENCES}

[1] D. McElreath, D. Doss, C. Jensen, M. Wigginton, R. Nations, \& J. Van Slyke. Foundations of emergency management. Kendall-Hunt, Dubuque, 2014.

[2] D. McElreath, C. Jensen, M. Wigginton, D. Doss, R. Nations, \& J. Van Slyke. Introduction to homeland security ( $2^{\text {nd }}$ ed.). CRC Press, Boca Raton, 2014.

[1] National Oceanic and Atmospheric Administration. Exxon Valdez oil spill. Online available from: http://response.restoration.noaa.gov/oil-and-chemical-spills/s 
ignificant-incidents/exxon-valdez-oil-spill.

[3] J. Wills. U.S. environmental history: Inviting doomsday. Edinburgh University Press, Edinburgh, 2013.

[4] R. Griffin. Management. (11 ${ }^{\text {th }}$ ed.). South-Western Cengage, Mason, 2013.

[5] M. Bell, D. Davis, \& T. Fletcher. A retrospective assessment of mortality from the London smog episode of 1952: The role of influenza and pollution. Environmental Health Perspectives, Vol. 112, No. 1, 6-8.

[6] K. Pickering \& L. An introduction to global environmental issues. ( $2^{\text {nd }}$ ed.). Routledge, New York, 1997.

[7] D. Doss. An investigation of adapting the software capability maturity model architecture and framework within traditional industrial environments. Northcentral University, Prescott, 2004.

[8] R. Kishore, E. Swinarski, E. Jackson, \& H. Rao. A quality-distinction model of IT capabilities: conceptualization and two-stage empirical validation using cmmi processes. IEEE Transactions on Engineering Management, Vol. 59, No. 3, 457-469.

[9] S. Zahran. Software process improvement: Practical guidelines for business success. Addison-Wesley, Boston, 1999.

[10] R. Salomone, M. Clasadonte, M. Proto, \& A. Raggi. Product-Oriented Environmental Management Systems (POEMS): Improving sustainability and competitiveness in the agri-food chain with innovative environmental management tools. New York, NY: Springer, New York, 2013.

[11] P. Weib \& J. Bentlage. Environmental management systems and certification. Baltic University Press, Uppsala, 2006.

[12] Environmental Protection Agency. Federal facility environmental management systems. Government Institutes, Rockville, 2000.

[13] F. Friedman. Freidman's guide to environmental management ( $11^{\text {th }}$ ed.). West Academic, St. Paul, 2011.

[14] M. Diaz \& J. Sligo. How software process improvement helped Motorola. IEEE Software, Vol. 1997, 75-81.

[15] J. Jiang, G. Klein, H. Hwang, J. Huang \& S. Hung. An exploration of the relationship between software development process maturity and project performance. Information \& Management, Vol. 41, 279-288.

[16] H. Kerzner. Using the project management maturity model: Strategic planning for project management. ( $2^{\text {nd }}$ ed.). Wiley, Hoboken, 2011.

[17] S. Marshall. \& G. Mitchell. An e-learning maturity model? Paper presented to the $19^{\text {th }}$ Annual Conference of the Australian Society for Computers in Learning in Tertiary Education. New Zealand, Auckland, 2002.

[18] C. Lutteroth, A., Luxton-Reilly, G., Dobbie, \& J. Hamer. A maturity Model for Computing Education. In Proceedings of the Ninth Australasian Computing Education Conference (ACE2007), Ballarat, Australia. CRPIT, 66. ACS. 107-114, 2007.
[19] W. Van Grembergen \& S. De Haas. Business strategy and applications in enterprise IT governance. IGI Global, Hershey, 2012.

[20] D. Doss. The capability maturity model as a criminal justice process improvement paradigm. University of South Africa, Pretoria, 2014.

[21] M. Mani, K. Lyons, \& R. Sriram. Developing a sustainability manufacturing maturity model. Online available from: http://ws680.nist.gov/publication/ get_pdf.cfm?pub_id=906033

[22] D. Doss \& R. Kamery. The capability maturity model: A valid architecture to support a baseline environmental maturity model. Proceedings of the Academy of Information and Management Sciences, Vol. 9, No. 2, 1-5.

[23] D. Doss \& R. Kamery. Implementation of the capability maturity model to support continuous process improvement tenets of the TQM philosophy. Proceedings of the Academy of Information and Management Sciences, Vol. 9, No. 2, 8-11.

[24] D. Doss \& R. Kamery. Adapting the capability maturity model (CMM) to unrelated industries as a process maturity framework. Proceedings of the Academy of Educational Leadership, Vol. 11, No. 1, 155-160.

[25] D. Doss \& R. Kamery. A review of existing capability maturity model (CMM) derivative frameworks. Proceedings of the Academy of Educational Leadership, Vol. 11, No. 1, 125-130.

[26] D. Doss \& R. Kamery. Derivation of the CMM to support the generation of a baseline IPMM. Proceedings of the Academy of Educational Leadership, Vol. 11, No. 1, 185-190.

[27] D. Doss \& R. Kamery. Exploring total quality management (TQM) and derivative frameworks of the capability maturity model. Proceedings of the Academy of Educational Leadership, Vol. 11, No. 1, 131-136.

[28] D. Doss \& R. Kamery. The capability maturity model (CMM) architecture and framework within traditional industrial environments: An overview. Proceedings of the Academy of Educational Leadership, Vol. 11, No. 1, 149-154.

[29] D. Doss, I. Chen, L. Holland. A proposed variation of the capability maturity model framework among financial management settings. Proceedings of the Academy of Accounting and Finance Studies, Vol. 13, No. 1, 15-18.

[30] J. Guangshe, X. Chen, C. Xue, J. Jianguo, J. Cao, \& K. Tang. Program management organization maturity integrated model for mega construction programs in China, International Journal of Project Management, Vol. 29, No. 7, 834-845

[31] F. Marx, F. Wortmann, \& J. Mayer. A maturity model for management control systems. Business \& Information Systems Engineering, Vol. 4, No. 4, 193-207.

[32] D. Pasalados \& R. Domingo. A maturity model for quality management to improve the manufacturing results. Annals of DAAM \& Proceedings, Vol. 2011, 375-376.

[33] V. Pikka, P. Iskanius, \& T. Page. The business enabling network - A tool for regional development. International Journal of Innovation and Regional Development, Vol. 3, No. $3,324-344$ 
[34] M. Saleh. Information Security Maturity Model. International Journal of Computer Science and Security, Vol. 5, No. 3, 316-337.

[35] D. Doss. Proposed model to support environmental management philosophies. Paper presented to the Mid-South Philosophy Conference, Memphis, TN, 2006.

[36] J. Cable. CSB report: Poor emergency planning made chemical accident worse. Online available from: http://ehstoday.com/news/ehs_imp_38176
[37] M. Fagel. Principles of emergency management: Hazard specific issues and mitigation. CRC Press, Boca Raton, 2012.

[38] Farazmand, A. Crisis and emergency management: Theory and practice ( $2^{\text {nd }}$ ed.). CRC Press, Boca Raton, 2014.

[39] R. Nandyal. CMMI: A framework for building world-class software and systems enterprises. Tata McGraw-Hill, New Delhi, 2004.

[40] P. Charantimath. Total quality management. (2 ${ }^{\text {nd }}$ ed.). Pearson, Delhi, 2011. 